\title{
Controversias socioambientales al sur de Chile: el caso de la crisis de la marea roja en la Isla Grande de Chiloé
}

\author{
Socio-environmental Controversies in Southern Chile: \\ the Case of the Red Tide Crisis on the Big Island of Chiloé
}

\author{
Marco Herrera Mansilla* (D) https://orcid.org/0000-0002-6556-8225
}

\section{Resumen}

El objetivo del artículo es explorar la controversia en torno a la floración de algas nocivas, también conocida como marea roja, que afectó la Isla Grande de Chiloé en 20I6. Desde las perspectivas de la ecología política, del postconstructivismo y de la teoría del actor-red, se examinan los discursos sobre este fenómeno y se describe la agencia que puede adquirir la materialidad en contextos de crisis. La metodología de este estudio de caso incluye el análisis de artículos de prensa, de registros audiovisuales, de documentos públicos, de observaciones en terreno y de entrevistas semiestructuradas. Los resultados muestran la emergencia de cuatro discursos asociados con distintas formaciones de redes entre agentes humanos y no humanos presentes en la controversia. La crisis refleja cómo se fueron politizando el conocimiento científico y otros saberes acerca de la marea roja, además de develar las pugnas de poder subyacentes sobre el mar interior de Chiloé. Una de las limitaciones del estudio, pendiente para futuras investigaciones, es que no indaga en los alcances de la crisis posconflicto.

Palabras clave: controversias socioambientales; floración de algas nocivas; marea roja; ecología política; postconstructivismo; teoría del actor-red.

\section{Abstract}

The objective of the article is to explore the controversy surrounding the harmful algal bloom, also known as the red tide that affected the Big Island of Chiloé in 2016. From the perspectives of political ecology, post-constructivism and actor network theory, the discourses on this phenomenon are examined and the agency that can acquire materiality in crisis contexts is described. The methodology of this case study includes the analysis of newspaper articles, audiovisual records, public documents, field observations, and semi-structured interviews. The results show the emergence of four discourses associated with different formations of networks between human and non-human agents present in the controversy. The crisis reflects how scientific and other knowledge about the red tide became politicized, in addition to revealing the underlying power struggles over the Chiloé inland sea. One of the limitations of the study is that it does not investigate the scope of the post-conflict crisis, elements that will remain pending for future research.

Keywords: socio-environmental controversies; harmful algae bloom; red tide; political ecology; post-constructivism; actor network theory.

Cómo citar: Herrera Mansilla, M. (2020). Controversias socioambientales al sur de Chile: el caso de la crisis de la marea roja en la Isla Grande de Chiloé. región y sociedad, 32, el343. doi: I0.22 198/rys2020/32/I343

* Universidad de la Frontera, Instituto de Desarrollo Local y Regional. Francisco Salazar Núm. 1145, C. P. 4811230. Temuco, Araucanía, Chile. Correo electrónico: m.herrera09@ufromail.cl

Recibido: 12 de mayo de 2020

Aceptado: 24 de noviembre de 2020

Liberado: 18 de diciembre de 2020

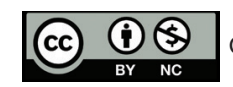

Esta obra está protegida bajo una Licencia Creative Commons Atribución-No Comercial 4.0 Internacional. 


\section{Introducción}

En la actualidad, los cambios que ha experimentado el planeta han causado una serie de emergencias que, dada su complejidad, conlleva el surgimiento de crisis en diversos ámbitos de la sociedad. Donde éstas se evidencian con mayor claridad, por sus características y su presencia en diferentes escalas, son las relacionadas con el medio ambiente. Esto se ha expresado en una serie de conflictos socioambientales que han impactado en los ecosistemas del planeta. Según Merlinsky (2017), dichos conflictos se originan a partir de disputas en el ámbito político en torno a los modos diferenciados de producción, apropiación, uso y significado de bienes naturales -como agua, bosques, fauna, mar y tierra- que se entrelazan con los procesos de acumulación de capital del modelo neoliberal, lo cual genera controversias sobre temas tan diversos como la instalación de megaproyectos de infraestructura, extracción de minerales, contaminación y daño ecológico por procesos productivos, sobreexplotación de recursos naturales, extinción de fauna silvestre e introducción de especies foráneas, por nombrar sólo algunos.

Según Escobar (2013) y Gudynas (2014), el actual contexto de crisis medioambiental presente en el mundo está conectado a un rasgo determinante de la modernidad: el dualismo naturaleza/sociedad, que pertenece a lo que Escobar (2013) denomina “dualismos ontológicos”. El autor afirma que éstos no sólo están en la base de nuestra imagen del mundo como mundo único -en referencia al concepto que utiliza John Law (2011, citado en Escobar, 2013)-, sino que también "subyacen a toda la estructura de instituciones y prácticas a través de las cuales se representa ese mundo único, efectuando al mismo tiempo un distanciamiento y una separación de los mundos que tejemos inevitablemente con otros y del mundo natural" (p. 18). En este sentido, estas formas de representar la realidad ambiental entran en tensión en contextos de crisis socioambientales, en las cuales es posible observar cómo se van entrelazando complejos entramados políticos, económicos, ambientales y tecnológicos en torno a la naturaleza. Estas diferentes representaciones son fuente de disputas constantes y tienen marcos de referencia inestables y cambiantes en momentos de crisis (Latour, 2008, p. 43). Al respecto, la propuesta de la presente investigación tiene como finalidad ampliar el análisis de las controversias socioambientales, describiendo la agencia que puede adquirir la materialidad en contextos de crisis y explicando cómo ésta entra en disputa en complejas relaciones de poder. Se tomará como caso de estudio una de las mayores crisis ambientales en la historia del sur de Chile. Ésta se debió a la floración de algas nocivas (FAN) que afectó a la isla Grande de Chiloé en 2016. Dado el grado de tensión existente alrededor del fenómeno, las controversias superan el ámbito de lo local para transformarse en debates a escala nacional que incluso han modificado políticas públicas y protocolos en materia ambiental y regulando actividades productivas en el territorio (Corte Suprema de Chile, 2018; Sepúlveda y Sundberg, 2017).

El objetivo es determinar cuáles son los discursos de los agentes respecto a las causas que provocan la FAN y sus efectos en la crisis socioambiental en la isla Grande de Chiloé durante 2016. La metodología de este estudio de caso incluye 
el análisis de contenido de artículos de prensa, de registros audiovisuales, de documentos públicos, de registro de actividades de observación y de entrevistas semiestructuradas.

El artículo se organiza en cinco apartados después de la presente introducción. En primer lugar, se hará referencia a los antecedentes del caso de estudio. Enseguida se desarrollará el marco conceptual desde la ecología política, el postconstructivismo y la teoría de actor red (TAR) a un mismo tiempo. En tercer lugar, se presentará la metodología de la investigación. En el cuarto apartado se analizarán los resultados obtenidos vinculando la teoría con las evidencias encontradas. Por último, se escriben las conclusiones.

\section{Antecedentes del caso de estudio}

La isla Grande de Chiloé $\left(42^{\circ}\right.$ y $43^{\circ}$ de latitud y $75^{\circ}$ y $73^{\circ}$ de longitud sur) se encuentra ubicada en el sur de Chile, en la región de Los Lagos (Gobernación Provincia de Chiloé, 2018). El territorio de Chiloé es un archipiélago formado por más de treinta islas, con una extensión de $9.181 \mathrm{kms}^{2}$, con una longitud de $180 \mathrm{~km}$ de norte a sur. De acuerdo con datos censales (Instituto Nacional de Estadísticas [INE], 2017), la provincia de Chiloé cuenta con 168185 habitantes, los cuales se dedican principalmente a actividades relacionadas con la agricultura, la ganadería, la silvicultura, la pesca y el comercio.

El evento de la FAN se ha presentado de forma cíclica durante las últimas cuatro décadas. Al principio sólo aparecía en la región de Magallanes, pero se ha expandido hacia las regiones de Aysén y Los Lagos (Buschmann, Farías, Tapia, Varela y Vásquez, 2016). Este fenómeno natural se caracteriza por la proliferación de microorganismos dañinos $\mathrm{y}$, dados sus efectos adversos en la salud, repercute en las actividades acuícolas y turísticas; también en poblaciones naturales de organismos marinos (Ministerio de Salud de Chile [MINSAL], 2008). Las floraciones producen toxinas que acumulan organismos bentónicos que se alimentan de fitoplancton, como los moluscos bivalvos (MINSAL, 2008). Los altos niveles de toxina en estos organismos pueden transmitirse a los niveles superiores de la cadena trófica y actuar como vectores que dan lugar a intoxicaciones

por veneno paralizante de mariscos (VPM). Éstas pueden incluso causar la muerte de quienes consumen esos organismos (Biblioteca del Congreso Nacional de Chile [BCN], 2016a; MINSAL, 2008).

La FAN de 2016 causó el mayor daño al ecosistema marino en Chiloé y en otras localidades de la región de Los Lagos, además de pérdidas económicas de la industria del salmón, de la pesca artesanal y de comunidades huilliches-lafquenches. Uno de los elementos centrales que se expresaron durante la dinámica de la controversia en la isla, fue establecer las causas de la emergencia y magnitud del fenómeno. Debido al alto grado de incertidumbre que causa la FAN, aparece en escena el conocimiento experto, el cual buscó reducir dicha incertidumbre y estabilizar los marcos de referencia en torno al evento, además de determinar que las causas de la crisis eran, en primera instancia, el fenómeno del Niño y el cambio climático. Además, las investigaciones detectaron la 
presencia de dos microalgas durante el desarrollo de la crisis. Una es la Pseudochatonella verruculosa, que está vinculada a la masiva mortandad de salmones en cultivo en el extremo norte del mar interior de Chiloé y en el Seno de Reloncaví; la otra es el dinoflagelado Alexandrium catenella, ${ }^{1}$ que ocasiona los brotes de toxina paralizante y su consiguiente efecto sobre la salud y la economía de la región (Espinoza y Besoaín, 2018). Diversos estudios a escala nacional se han concentrado en investigar dicho dinoflagelado (Armijo, Bravo y Molina, 2018; Espinoza y Besoaín, 2018; Guzmán, Espinoza-González, Pinilla, Calderón, Cáceres, Iriarte, Muñoz, Martínez, Hernández, Tocornal y Carbonell, 2018; Masotti, Uribe, Malhue, Vera, y Cádiz, 2018) y concluyeron que ese organismo, productor del VPM, posee un ciclo de vida complejo que involucra la formación de quistes de resistencia producto de la reproducción sexual, los cuales, dado su grado de toxicidad, se presentan como uno de los mayores riesgos ambientales para el ecosistema marino de Chile (Armijo, Bravo y Molina, 2018).

Las consecuencias del evento comenzaron a presentarse durante las primeras semanas de febrero de 2016 con la muerte de salmones en cultivo que causó la Pseudochatonella verruculosa en el norte del mar interior de Chiloé y en el Seno de Reloncaví (Buschmann, Farías, Tapia, Varela y Vázquez, 2016). Luego, a partir de la última semana de febrero de 2016, comenzó a manifestarse la floración del dinoflagelado tóxico Alexandrium catenella que impactó con fuerza la región de Los Lagos y alcanzó por primera vez la región de Los Ríos (véase figura 1). Después, desde principios de abril, se observaron, además, mortalidades de moluscos bivalvos, aves y peces en Chiloé y en otras localidades de la región de Los Lagos (Buschmann et al., 2016).

Esta situación desencadenó una serie de efectos sociales, económicos y medioambientales. Diversos actores se vieron impedidos de continuar con las actividades económicas relacionadas con la extracción de recursos del mar. Se vio afectado todo el encadenamiento productivo del sector de la pesca, y la población dejó de consumir productos del mar debido a la alerta sanitaria sobre los potenciales riesgos a la salud. El gobierno de Chile, como forma de paliar los efectos sociales y económicos de la crisis, declaró zona de catástrofe ${ }^{2}$ a 13 comunas de la región de Los Lagos. A inicios de mayo de 2016 comenzaron las movilizaciones de los sindicatos de pescadores artesanales, de recolectores y de comerciantes de productos del mar afectados por la prohibición de extraer mariscos y otros productos marinos (Aqua, 2016b). El movimiento siguió su escalada y se fueron sumando más gremios hasta paralizar la región con cortes de rutas y caminos, además de la toma de algunos puertos que por cerca de 18 días impidieron el tránsito desde y hacia casi cualquier lugar. Al principio, los puntos más conflictivos fueron Pargua, Maullín y el archipiélago de Chiloé; luego lo fue

1 Alexandrium catenella es un dinoflagelado productor del veneno paralizante de los mariscos (VPM) a escala mundial, cuyo complejo tóxico lo conforman más de 20 compuestos denominados saxitoxinas. Estos compuestos actúan bloqueando los canales de sodio de la membrana celular e inhibiendo los impulsos nerviosos y la contracción muscular (Guo, Uehara, Ravidran, Bryan, Hall y Moczydlowski, 1987; Pizarro, Garrido, Zamora, Alarcón, Raimapo, Salgado, Pacheco, Guzmán, Paz, Álvarez y Faure, 2015).

2 Decreto Supremo del Ministerio del Interior y Seguridad Pública Núm. 409 del 29 de abril de 2016 (Biblioteca del Congreso Nacional de Chile, 2016b). 
Figura 1. Zona afectada por la FAN durante la crisis de 2016

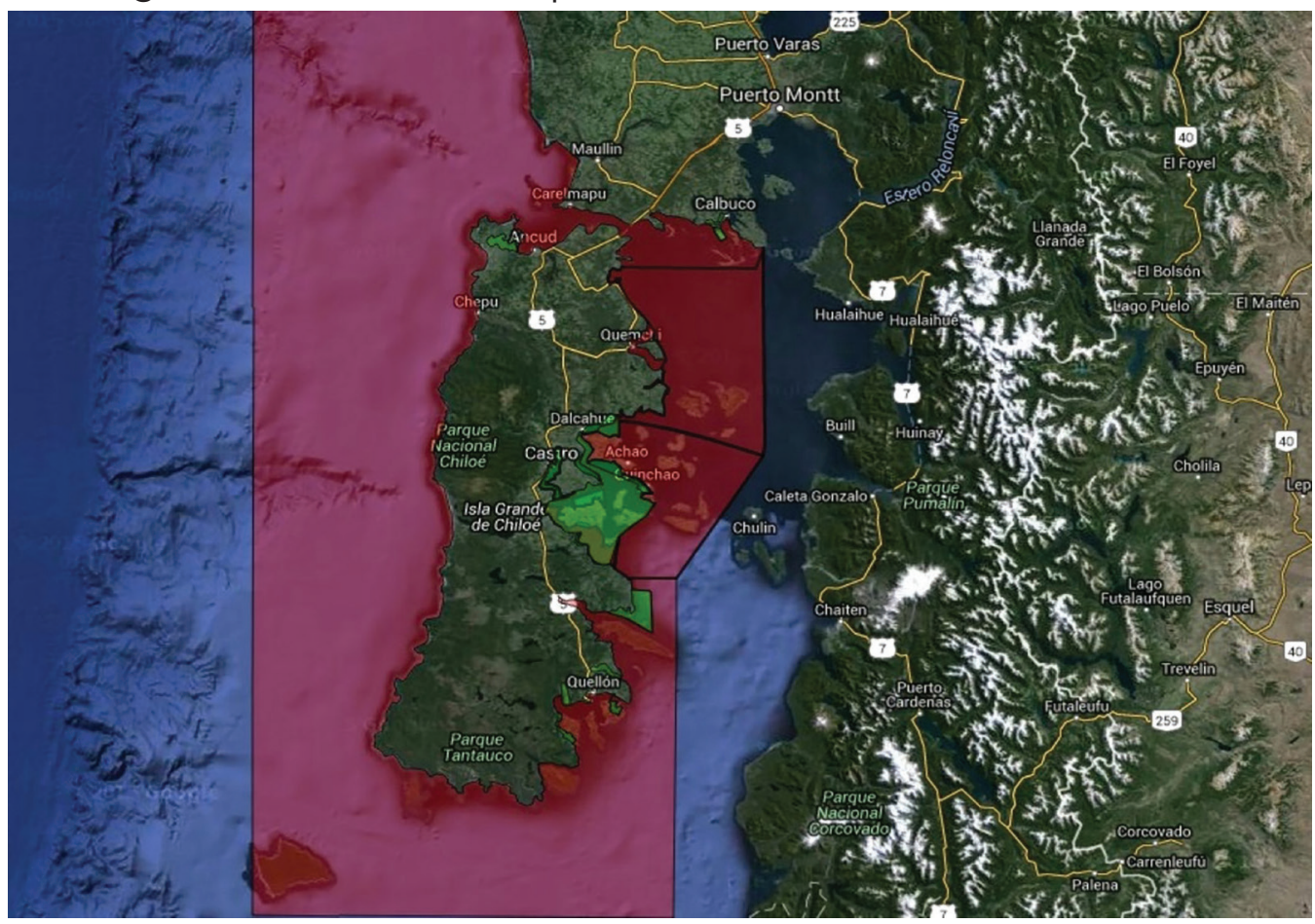

Fuente: Aqua (2016a).

toda la región de Los Lagos, situación que se mantuvo durante las negociaciones por compensaciones económicas entre los sindicatos de pescadores artesanales y el Estado (Aqua, 2016b).

Un hecho determinante en el desarrollo de los acontecimientos fue la autorización de parte del Estado del vertimiento de salmones muertos en altamar que solicitó la industria salmonera para evitar una emergencia ambiental en los centros de cultivo. La Armada de Chile y el Servicio Nacional de Pesca (SERNAPESCA) (Dirección General del Territorio Marítimo y Marina Mercante [DIRECTEMAR], 2016) autorizaron a las empresas salmoneras el vertimiento de 9000 toneladas de salmones descompuestos en alta mar, de las cuales sólo 4655 fueron vertidas. Según SERNAPESCA, la operación se hizo dentro de las normas correspondientes y se debió a la muerte de salmones a causa de la floración de microalgas nocivas, como la Chattonella sp y la Leptocylindrus. De acuerdo con algunos artículos de prensa (Martínez, 2016), esta mortalidad masiva comenzó entre el 21 y el 27 de enero, y desde el 22 de febrero la microalga Chattonella $s p$ tuvo una floración explosiva que afectó 45 centros de cultivos. Los peces muertos fueron retirados el 24 de marzo. Dijo la autoridad que más de $50 \%$ de éstos se destinó a plantas reductoras, más de $30 \%$ a vertederos y cerca de $13 \%$ fue vertido al mar. 
SERNAPESCA, en conjunto con la Armada de Chile, decidieron que el vertimiento de los peces muertos en el océano se hiciera a 60 millas de la costa para evitar cualquier riesgo a la salud humana, según lo estipulado en el Protocolo de Londres, que regula el vertimiento de desechos en el mar a nivel internacional (Aqua, 2016c; Organización Marítima Internacional [OMI], 2020). El lugar elegido sería una fosa submarina a 75 millas mar adentro al noreste de la isla de Chiloé, en específico desde Faro Punta Corona (comuna de Ancud), zona que, según las autoridades pesquera y marítima, reúne las garantías técnicas para no afectar actividades del sector pesquero, vías de navegación o de interés medioambiental (Aqua, 2016c). Sin embargo, la decisión desencadenó una serie de cuestionamientos. Los movimientos sociales comenzaron a apuntar como responsable de la crisis a la industria del salmón, con lo cual se logró desestabilizar el argumento del fenómeno del Niño y el cambio climático como causantes de la crisis. La investigación de la ONG Ambientalista Greenpeace sobre la crisis ayudó a reforzar el argumento de dichos movimientos. Ésta concluyó que "si bien el bloom [la floración] de algas estaba presente en la zona con anterioridad al vertimiento, el salmón vertido actuó como un 'fertilizante' de éste aumentando su magnitud, intensidad y alcance" (Greenpeace, 2016a). Agrega que la decisión del gobierno de visar el vertido de los peces en descomposición en la misma zona que ya presentaba la floración, empeoró la situación y desencadenó la crisis social y ambiental en Chiloé (Greenpeace, 2016a).

Antes de la publicación de los resultados de la investigación de Greenpeace, el Ministerio de Economía había convocado, a través de la Academia de Ciencias de Chile, un Comité Científico independiente para evaluar el desastre ambiental (Buschmann et al., 2016). El 25 de mayo zarpó desde la ciudad de Talcahuano el buque AGS-61 Cabo de Hornos, en una expedición oceanográfica diseñada y ejecutada por miembros de dicho Comité con el apoyo de diversos centros de investigación del país, para realizar el estudio prospectivo del evento de la marea roja ocurrido en la región de Los Lagos (Buschmann et al., 2016).

La comisión de expertos del gobierno centró su análisis principalmente en dos microorganismos: la microalga Pseudochatonella verruculosa y el dinoflagelado tóxico Alexandrium catenella. Según la comisión de expertos (Buchmann et al., 2016) "la primera de ellas (Pseudochatonella verruculosa) tuvo como consecuencia una masiva mortandad de salmones en cultivo en el extremo norte del Mar Interior de Chiloé y Seno de Reloncaví" y "el dinoflagelado tóxico alexandrium catenella, impactó fuertemente a la región de Los Lagos y alcanzando por primera vez a la región de Los Ríos" (p. 1). En este aspecto, y tras 11 semanas de investigación de la marea roja, el comité de científicos independientes presentó un informe de avance al Ministerio de Economía, Fomento y Turismo, el cual concluyó que el vertimiento de salmones no fue un agente causal de la marea roja ( $E$ l Mostrador, 2016a). Los resultados que entregó la comisión científica motivaron diversas manifestaciones en Chiloé por parte de ONG ambientalistas, de movimientos sociales y de autoridades locales, los cuales no compartían los resultados del estudio. Estas desavenencias tensionaron aún más el contexto de la crisis. 


\section{Marco conceptual}

La presente investigación está enmarcada en las perspectivas de la ecología política, el postconstructivismo y la teoría de actor-red (TAR), entendiendo que estos enfoques permiten conectar las redes de poder presentes en la controversia con la agencia de la FAN, la cual se encuentra mediada por formaciones heterogéneas de agentes, sean estos humanos o no humanos, como plantea la TAR. Lo anterior nos da un marco comprensivo de las relaciones de poder alrededor de la naturaleza y su conexión material articulada a soportes tecnológicos, científicos y biológicos en torno a las causas y los efectos de este agente no humano. En este sentido, comprender estos complejos procesos de hibridación que se configuran en los conflictos socioambientales, plantea ir un paso más allá, entendiendo el vínculo entre los seres humanos y las condiciones naturales y materiales, como se observa en el caso de la crisis de 2016 en la isla Grande de Chiloé. Al respecto, Bińczyk (2013) señala que, en la actualidad, el mundo vive en relación con conexiones híbridas y ontologías heterogéneas, donde infraestructuras tecnológicas se encuentran entrelazadas con instituciones, seres naturales (como microorganismos u otras especies), decisiones legales y políticas. En la era de la globalización, estos elementos son interdependientes, y la dimensión natural se entrelaza con la dimensión política y jurídica. En este sentido, el planteamiento de la ecología política (EP) de politizar la naturaleza $\mathrm{y}$, en específico, las asimetrías de poder que existen en torno a la distribución de los recursos ambientales y los efectos de la degradación ambiental, permiten entender que la naturaleza es un fenómeno inevitablemente político (Bustos, Prieto y Barton, 2017, p. 19).

Por otro lado, hay perspectivas académicas dentro del amplio proyecto de desestabilización de los dualismos ontológicos -que han tenido un aumento interesante en el último tiempo- bajo posturas posconstructivistas, posdualistas, neorrealistas y posthumanas. Otras destacan la amplia gama de agencias asociada con lo no humano y la multiplicidad de formas en que el mundo está “ensamblado" (Escobar, 2016; Latour, 2012, p. 117). Uno de los autores que realiza una descripción en conjunto entre la EP y el postconstructivismo es Arturo Escobar (2010), quien las denomina ecologías políticas postconstructivistas, planteando que éstas se construyen junto a los esfuerzos realizados para superar problemas creados por el constructivismo, radicalizándolos al tiempo que vuelve a plantear preguntas sobre "lo real”. Como sugiere Escobar (2010), esta EP emerge de cambios significativos en la teoría social, en concreto del llamado "giro ontológico" y de las "ontologías planas". Algunas tendencias recientes discuten la multiplicidad de mundos socio-naturales o de culturas-naturalezas, ontologías relacionales versus dualistas, formas de análisis estructurales versus de análisis de redes, e incluso una renovación de la pregunta sobre qué constituye vida. Mientras estas preguntas aparecen insuperables en términos teóricos, lo social emerge con claridad debido en gran medida a la presencia de movimientos sociales (Escobar, 2010). Al respecto, ampliar el marco analítico de la EP mediante el postconstructivismo permite entender cómo las asimetrías de poder en torno a la naturaleza se encuentran entrelazadas de forma inherente a 
condiciones materiales (objetos, dispositivos sociotécnicos, microorganismos), de modo que es posible observar cómo se configuran versiones de la realidad sostenidas tanto discursiva como materialmente que entran en disputa en contextos de conflictividad ambiental. En este aspecto, uno de los elementos centrales de las posturas posconstructivistas es su deseo de incluir la materialidad en las explicaciones acerca de la construcción de la realidad (Knol, 2011). Sin embargo, este enfoque no se centra en las teorías científicas propiamente dichas, sino más bien en las prácticas de laboratorio, donde se utilizan conceptos y metáforas constructivistas y antiesencialistas, como los términos "fabricación”, “cuasi-objeto”, “hechos”, “traducción”, “actante”, "red heterogénea”, "agencia”, "factores no humanos", entre otros (Knol, 2011). En este sentido, Latour y Woolgar (1995), Mol (1999) y Sepúlveda y Sundberg (2017) describieron por primera vez la microfabricación de hechos científicos y mostraron cómo éstos eran fabricados y luego estabilizados a través de un esfuerzo sostenido e incierto, con la intervención de agentes humanos y no humanos. Una vez estabilizados, tales "hechos" parecían adquirir una existencia previa al ser borradas las huellas de su fabricación, proceso al cual Latour (2001) llama la "caja negra” de las ciencias.

Además del giro hacia la materialidad que caracteriza a los estudios posconstructivistas, una segunda característica unificadora de estas obras se relaciona con su intención de explicar la ciencia, la naturaleza y la política en conjunto (Knol, 2011), lo cual deja atrás las nociones preestablecidas de estos tres elementos. Si la naturaleza, la ciencia y la política son coproducidas, esto significa que no existe la "naturaleza" como algo exterior (Asdal, 2003; Latour, 2004); más bien debemos ser conscientes de la agencia performativa de la ciencia y la política para coproducir un ecosistema o realidad ambiental (Knol, 2011).

Knol (2011) plantea que los estudios posconstructivistas pueden dar una idea de cómo la ciencia y la política coproducen realidades sobre la naturaleza. A través de los estudios de las prácticas científicas, materiales y procesos de categorización, un enfoque posconstructivista puede hacer visibles las conexiones entre las prácticas locales y el pensamiento político a nivel macro que se mantiene en redes de producción local. Dicho enfoque de investigación se presenta como local y global a un mismo tiempo, y tiene como objetivo construir conexiones sistemáticas entre los micromundos de la práctica científica y las macrocategorías del pensamiento político (Jasanoff, 2004).

Por otro lado, Bińczyk (2013) considera, como ejemplos de pensamiento posconstructivista, los estudios de ciencia y tecnología (STS por sus siglas en inglés) y la TAR de Bruno Latour (2008), ya que permiten representar tanto ciencia y tecnología como esferas de la práctica colectiva, materialmente situada y enraizada de forma instrumental. En este aspecto, la TAR ha presentado un desarrollo importante dentro del campo de los estudios de ciencia y tecnología, caracterizado por tratar de comprender las relaciones entre redes y ensamblajes de actores humanos y no humanos que comparten la misma participación en la conformación de los problemas de la ciencia (Forlano, 2017). Desde el punto de vista de la TAR, es habitual hablar sobre actores o actantes, mediadores e intermediarios que no necesariamente son humanos. De hecho, a veces la hete- 
rogeneidad de estas entidades se encuentra resaltada: tanto humanos como no humanos pueden ser híbridos; por lo tanto, desde la perspectiva de la TAR, son los no humanos y sus relaciones específicas con los humanos lo que conforma lo social y, como resultado, las formas en que el conocimiento científico y la tecnología adquieren "valor duradero" (Forlano, 2017).

La producción de conocimiento es un elemento relevante en el contexto de las controversias socioambientales. Bustos, Prieto y Barton (2017) señalan que dicha producción es tanto acerca de las prácticas concretas en los ecosistemas como de la forma en que es producido el conocimiento mismo y sus implicaciones en dar sentido y significado a los actores involucrados. Lo anterior resulta importante si se acepta que los mecanismos de producción de conocimientos per se se configuran en torno a ciertos modos de conocer una realidad ambiental y de privilegiar ciertas soluciones por sobre otras (Bustos, Prieto y Barton, 2017), lo cual abre el debate en torno a la objetividad de la configuración de un problema ambiental. En definitiva, las desiciones sobre qué mecanismos permitirán conocer una realidad ambiental y sus potenciales concecuencias, en última instancia es una desición política (Campbell y Godfrey, 2010).

Durante la controversia de 2016 en Isla Grande de Chiloé, se fracturó el conocimiento científico sobre las causas que originaron la emergencia de la FAN, situación que provocó versiones alternas que entraron en disputa y se materializaron durante la crisis. En este aspecto, Mol (1999) refiere que si la realidad se hace a través de distintas redes de prácticas donde están insertas, y si ésta es "histórica, cultural y materialmente localizada", también es múltiple. Múltiple pero no plural, ya que la noción de multiplicidad, considera no la materialización de distintos atributos de un mismo objeto unificado, sino la materialización de diferentes versiones de dicho objeto: son “objetos diferentes y aun relacionados. Son formas múltiples de la realidad. Si la realidad es múltiple, también es política (Sepúlveda-Luque et al., 2018).

\section{Metodología}

La investigación es diacrónica, cualitativo-descriptiva e interpretativa. En ella se analizó la controversia como estudio de caso. En cuanto a la unidad de análisis, se tomó como criterio el espacio-tiempo comprendido entre los meses de enero y diciembre de 2016, periodo en que se desarrolló la crisis. Aquí la FAN será entendida como el objeto simbólico que produce sentidos. Y se verá cómo éste está investido de significado para y por sujetos que explicitan en el texto organizado los gestos de interpretación que relacionan sujeto y sentido (Orlandi, 2012, p. 33). El análisis se centró en los discursos de los actores que refieren sobre la FAN, a qué atribuyen las causas de su emergencia y desde qué lugar se produce el discurso. Lo anterior se realizó a través de la siguiente secuencia:

a) Revisión y análisis de artículos de prensa. Se revisaron artículos de prensa de medios electrónicos que cubrieron los acontecimientos de la marea roja entre enero y diciembre de 2016. Se consideraron los artículos electrónicos 
de aqua.cl -portal que cubre noticias del rubro acuícola-, de elmostrador.cl y de biobiochile.cl. Se seleccionó una muestra de 50 artículos (véase tabla 1) que registraron el desarrollo de la crisis, los cuales fueron tratados mediante análisis de contenido.

Tabla 1. Artículos que en medios electrónicos registraron la crisis de la marea roja

\begin{tabular}{|c|c|c|c|c|c|}
\hline \multicolumn{6}{|c|}{ Portal aqua.cl (vínculos de acceso) } \\
\hline 1 & \multirow{10}{*}{$\begin{array}{c}\text { https://n9.cl/a0qp2 } \\
\text { https://n9.cl/bzwki } \\
\text { https://n9.cl/rd5t } \\
\text { https://n9.cl/vtaoa } \\
\text { https://n9.cl/nywb } \\
\text { https://n9.cl/16khq } \\
\text { https://n9.cl/9xfu4 } \\
\text { https://n9.cl/81 mdu } \\
\text { https://n9.cl/89c9e } \\
\text { https://n9.cl/eshlh }\end{array}$} & 11 & \multirow{10}{*}{$\begin{array}{c}\text { https://n9.cl/1sem } \\
\text { https://n9.cl/jqyiu } \\
\text { https://n9.cl/jimz } \\
\text { https://n9.cl/2kdh0 } \\
\text { https://n9.cl/5xh0 } \\
\text { https://n9.cl/5wyva } \\
\text { https://n9.cl/tpn5y } \\
\text { https://n9.cl/4i8ui } \\
\text { https://n9.cl/oe6b } \\
\text { https://n9.cl/hc337 }\end{array}$} & 21 & \multirow{10}{*}{$\begin{array}{c}\text { https://n9.cl/mb80s } \\
\text { https://n9.cl/kff3 } \\
\text { https://n9.cl/8lwe1 } \\
\text { https://n9.cl/h05hc } \\
\text { https://n9.cl/g7o4 } \\
\text { https://n9.cl/otn5x } \\
\text { https://n9.cl/3pcxr } \\
\text { https://n9.cl/mvbib } \\
\text { https://n9.cl/gg8a2 } \\
\text { https://n9.cl/jdu2 }\end{array}$} \\
\hline 2 & & 12 & & 22 & \\
\hline 3 & & 13 & & 23 & \\
\hline 4 & & 14 & & 24 & \\
\hline 5 & & 15 & & 25 & \\
\hline 6 & & 16 & & 26 & \\
\hline 7 & & 17 & & 27 & \\
\hline 8 & & 18 & & 28 & \\
\hline 9 & & 19 & & 28 & \\
\hline 10 & & 20 & & 30 & \\
\hline \multicolumn{6}{|c|}{ Portal biobiochile.cl (vínculos de acceso) } \\
\hline 1 & \multirow{5}{*}{$\begin{array}{l}\text { https://n9.cl/cvfoi } \\
\text { https://n9.cl/bbyk9 } \\
\text { https://n9.cl/q1jxi } \\
\text { https://n9.cl/j75hy } \\
\text { https://n9.cl/mapf }\end{array}$} & 6 & \multirow{5}{*}{$\begin{array}{l}\text { https://n9.cl/m7g7t } \\
\text { https://n9.cl/xry5 } \\
\text { https://n9.cl/gqc0c } \\
\text { https://n9.cl/fhjcz } \\
\text { https://n9.cl/sz7k2 }\end{array}$} & 11 & \multirow{5}{*}{$\begin{array}{l}\text { https://n9.cl/sbmvh } \\
\text { https://n9.cl/ytqk } \\
\text { https://n9.cl/m32or }\end{array}$} \\
\hline 2 & & 7 & & 12 & \\
\hline 3 & & 8 & & 13 & \\
\hline 4 & & 9 & & & \\
\hline 5 & & 10 & & & \\
\hline \multicolumn{6}{|c|}{ Portal elmostrador.cl (vínculos de acceso) } \\
\hline 1 & \multirow{3}{*}{$\begin{array}{l}\text { https://n9.cl/3nj0c } \\
\text { https://n9.cl/nmdxd } \\
\text { https://n9.cl/24k0b }\end{array}$} & 4 & \multirow{3}{*}{$\begin{array}{l}\text { https://n9.cl/f5mxj } \\
\text { https://n9.cl/68t0 } \\
\text { https://n9.cl/0vxmn }\end{array}$} & \multirow[t]{3}{*}{7} & \multirow[t]{3}{*}{ https://n9.cl/3y4z } \\
\hline 2 & & 5 & & & \\
\hline 3 & & 6 & & & \\
\hline
\end{tabular}

Fuente: elaboración propia.

De acuerdo con lo anterior, los periodos de mayor producción en estos medios (véase figura 2) fueron los meses de abril, mayo y junio, con 66\% (sólo el mes de mayo concentró $48 \%$ ) en pleno desarrollo de la crisis. Por otro lado, durante septiembre (14\%) y noviembre (10\%) se presentó una nueva activación en la producción en los medios de prensa, periodo durante el cual la ONG Ambientalista Greenpeace y la comisión científica encargada por el gobierno publicaron los informes de investigación de la marea roja. 
Figura 2. Producción en medios de prensa electrónicos analizada durante el desarrollo de la crisis de la marea roja de 2016

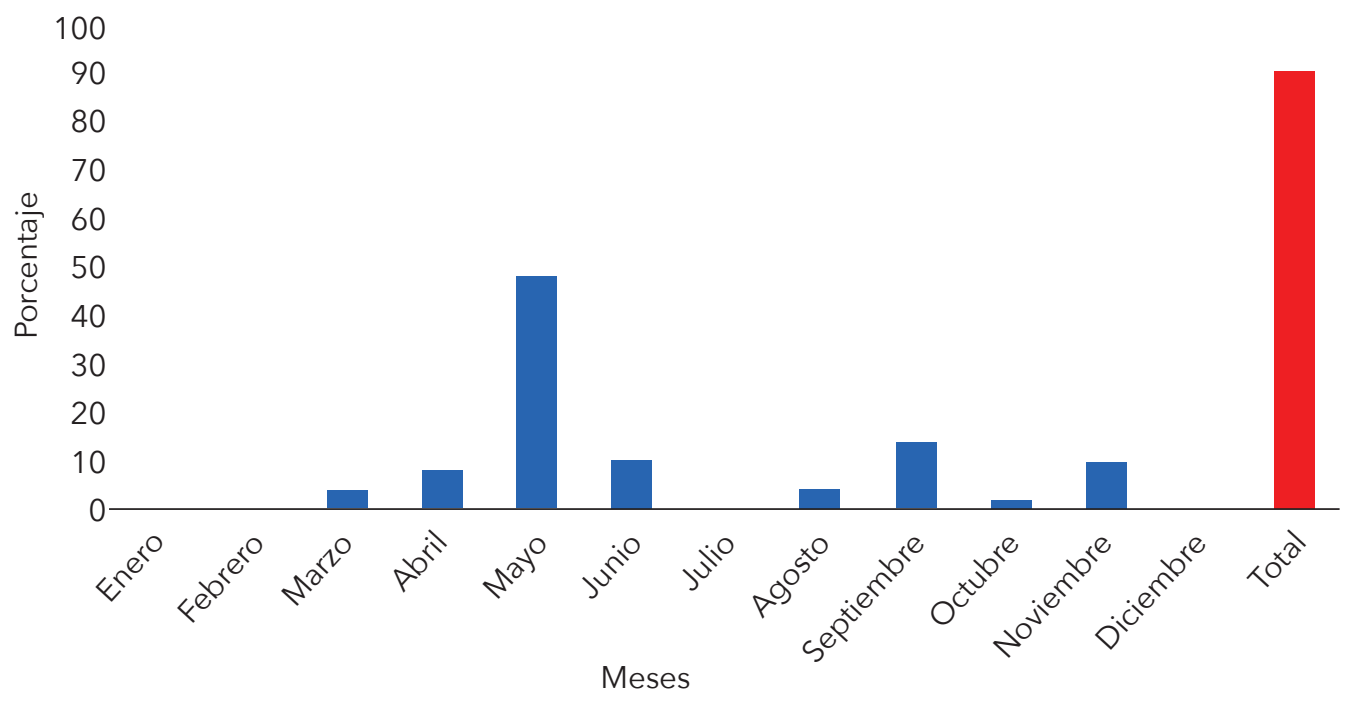

Fuente: elaboración propia.

b) Selección y análisis de registros audiovisuales. Se revisaron los registros audiovisuales que captaron los acontecimientos de la crisis de la marea roja. Se analizó el contenido de 10 registros audiovisuales publicados en YouTube, con entrevistas a agentes claves y debates, de los canales de CNNChile, Greenpeace Chile, InetChile (2 registros), Canal5Chile, Prensa Chiloé, Décima TV y de tres canales ciudadanos.

c) Análisis de documentos públicos y de organizaciones de la sociedad civil. Se analizó el contenido de documentos que emitieron instituciones públicas, como sentencias judiciales, decretos supremos y documentos de la Contraloría General de la República. También se incluyeron los informes del comité científico, el reporte de la investigación de Greenpeace y el informe de la misión de observación del Instituto Nacional de Derechos Humanos (INDH) sobre la situación socioambiental de la región de Los Lagos. Se seleccionaron siete documentos relevantes por la información que proporcionan, algunos de los cuales actuaron como mediadores durante la controversia.

d) Observación de actividades relacionadas con la FAN. Se participó en tres actividades que tratan sobre el fenómeno de la marea roja. Entre éstas, se encuentran cafés científicos y encuentros de diálogo en los que se registran posturas e intercambios de opinión de los participantes sobre el tema. Se analizó el contenido de los registros de las observaciones y de las grabaciones de dichas actividades.

e) Entrevistas a actores claves. Se realizaron entrevistas semiestructuradas para reconstruir los hechos a través de las experiencias de los actores. La finalidad 
fue explorar las visiones, significados y posturas acerca de la crisis de 2016. Se realizaron cinco entrevistas con informantes claves que estuvieron involucrados en el desarrollo de la crisis. El criterio de selección de los actores se basó en personas que estuvieron involucradas en una primera línea en la controversia, además de representar los distintos sectores del conflicto los cuales, dada la riqueza de información que manejan, son importantes para los fines de la investigación.

Mediante el programa Atlas.ti 7, el material fue codificado y categorizado para organizarlo e identificar tendencias y discontinuidades. Por otro lado, con el programa NodeXL -que es una extensión de Excel- primero se diseñó una cartografía ingresando a los agentes identificados en la controversia y sus discursos sobre la FAN. Luego se generaron los grafos con los agentes, agrupándolos según sus correspondientes posturas.

\section{Resultados}

Los resultados reflejan la emergencia de cuatro discursos argumentativos articulados a las causas y los efectos de la FAN. Estos argumentos fueron categorizados bajo los conceptos FAN y cambio climático, FAN y vertimiento de salmones, FAN y los procesos de la industria salmonera y FAN y agencia del mar de Chiloé. Lo anterior se aprecia en la figura 3, donde se muestran los agentes y sus discursos desplegados en una cartografía, lo cual permite observar cómo se agrupan aquéllos en cada una de las posiciones en la controversia.

En relación con la visualización de los datos, los tamaños de los círculos indican la cantidad de agentes que asociaron las causas de la FAN con cada una de las cuatro categorías definidas en el análisis de contenido. Mientras más grande es el círculo, mayor es la cantidad de actores que atribuyeron las causas a dicha categoría. A continuación, abordaremos en detalle cada uno de los discursos.

FAN y cambio climático

Este argumento conjuga a un importante grupo de agentes vinculados a la academia, al Estado y a la industria salmonera y mitilicultora asentada en la región. Al comienzo de la crisis, los centros de investigación, además de los expertos en temas marinos, afirmaron a partir del conocimiento existente, que la causa de la crisis se debía sobre todo al fenómeno del Niño y al cambio climático. Los primeros en pronunciarse en los medios de comunicación fueron los miembros del Colegio de Biólogos. Dijeron que entre los factores respaldados de forma científica que causan la marea roja, están "el calentamiento global, acidificación, un extremo fenómeno de El Niño (señalado como Godzilla por la NASA) y eutrofización de las aguas interiores" (Aqua, 2016d). En una primera instancia, esta versión "transportó significado o fuerza sin transformación” (Latour, 2008), información que fue "intermediada", lo cual amplió de esta forma la red de agentes en torno a este discurso: 


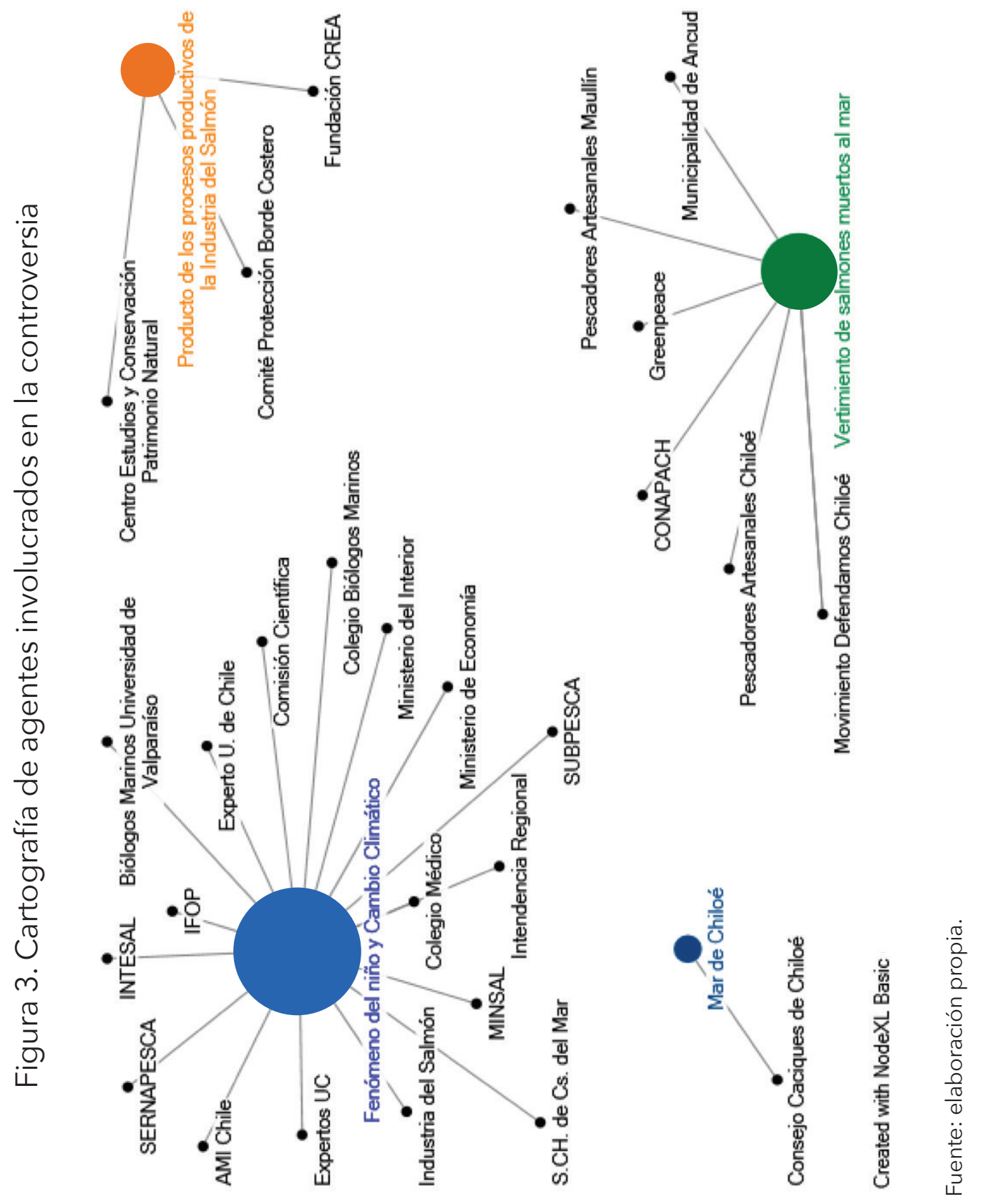


pero a ver, era un fenómeno del Niño nunca antes visto, el fenómeno del Niño más grande de la historia y aparte hubo unas condiciones súper particulares de vientos que venían desde el sur, temperaturas altísimas, luminosidad [...] fue [...] una tormenta perfecta. (Director territorial de SalmonChile, comunicación personal, 15 de julio de 2019)

Sin embargo, este discurso es puesto en tela de juicio por parte de la ciudadanía cuando las autoridades visaron el vertimiento de salmones muertos, lo cual ocasionó la articulación entre el Estado y la academia con el objetivo de coproducir nuevo conocimiento y establecer si existía o no relación entre la marea roja y dicho vertimiento. Según la Comisión de Expertos conformada para estos fines, el vertimiento de salmones, realizado a 75 millas náuticas al oeste de la costa de Chiloé, "no tiene relación directa con las floraciones de algas nocivas en la región" (Casas, 2016). Esta conclusión tradujo la información al aportar un nuevo significado a este hecho, siendo intermediada en la red a través de las instituciones del Estado, según se aprecia en la siguiente cita del exministro de Economía de la época:

Se destinó una importante cantidad de recursos para investigar esto y un equipo de científicos de la Universidad Austral de Chile (UACh) y de la Universidad de Los Lagos (Ulagos) ha ido monitoreando la emergencia, y por dónde avanzan las corrientes que llevarían la marea roja, por lo que no habría condiciones para explicar una relación de causa-efecto entre ambos eventos. (Aqua, 2016e)

Sin embargo, continuaron los cuestionamientos de distintas organizaciones de la sociedad civil y tuvieron un efecto desestabilizador del discurso del cambio climático, lo cual llevó a la industria salmonera a utilizar conocimiento experto transnacional sobre marea roja como un esfuerzo por sostener esta versión de los acontecimientos:

Por ejemplo [...] cuando recién pasó lo de la marea roja, trajimos a los principales expertos mundiales en marea roja, gallos gringos australianos. Hicimos un seminario para la industria, pero también hicimos un seminario donde invitamos exclusivamente a trabajadores, a pescadores artesanales para que ellos supieran de primera fuente, pudieran preguntar sin tapujos lo que quisieran. (Director territorial de SalmonChile, comunicación personal, 15 de julio de 2019)

En síntesis, este discurso, la acción, entendida como la red de entidades (humanas y no humanas) que van ensamblando y performando esta versión de los hechos, evidencia una trama que conecta discursiva y materialmente academia, Estado e industria salmonera, que a través de la coproducción de conocimiento buscaron sostener que la FAN se presentaba más bien por condiciones naturales externas dadas en un contexto de cambio global y no por factores y decisiones tomadas en el ámbito local. Este discurso buscaba establecer una postura despolitizada de la crisis. 
FAN y vertimiento de salmones

El vertimiento de salmones marcó la dinámica de la controversia. Algunas organizaciones de la sociedad civil y ONG cuestionaron la decisión. Los pescadores artesanales fueron observadores de los alcances de la marea roja y, mediante distintas estrategias de presión y protesta, cerraron los accesos a la isla y señalaron como responsables de la crisis a la industria salmonera y al Estado por autorizar el vertimiento. Según Latour (2008), en las controversias deben calificarse a otros agrupamientos como "vacíos, arcaicos, peligrosos, obsoletos, etc." (p. 54). Sin embargo, en el caso de la pesca artesanal, además de utilizar distintas estrategias de presión, tuvieron la capacidad de desterritorializar la crisis en distintos niveles, primero a nivel político, realizando posicionamientos fuera del territorio, como el lobby con parlamentarios en el Congreso Nacional y, segundo, a nivel científico-tecnológico, donde se articularon con la ONG Ambientalista Greenpeace para producir conocimiento mediante un estudio independiente del evento que resultó en el establecimiento de metas que tenían la finalidad de responsabilizar de la crisis al Estado y a la industria salmonera. Lo anterior lo describe la expresidenta de la Confederación Nacional de Pescadores Artesanales de Chile (CONAPACH):

Nosotros hablamos con Greenpeace en Valparaíso. En ese tiempo estaba el Samuel estaba el Samuel Leiva de jefe de la región, le llaman ellos, al país, estaba de jefe de la región. Le pedimos que ellos hicieran una investigación y ellos vinieron [...], ellos dijeron, bueno Greenpeace hizo su investigación y también deliberó lo mismo que decíamos nosotros, que no fue ni el cambio climático ni la marea roja, sino que fue producto de la contaminación que tiraron [...] los barcos. (Comunicación personal, 29 de junio de 2019)

Corroborando esta postura, Greenpeace señaló que "si bien la evidencia permite afirmar que la zona ya estaba afectada por bloom de algas, la autorización por parte del gobierno de verter casi 5000 toneladas de salmones actuó como un fertilizante potenciador de la marea roja" (Aqua, 2016f). En los términos planteados por Latour (2008), el proceso de traducción que generó el estudio de Greenpeace transportó un nuevo significado sobre las causas del evento, donde otros agentes actuaron como intermediarios de ésta información, como se aprecia en la siguiente cita del movimiento ciudadano Defendamos Chiloé: “El informe del comité científico y la Subpesca tienen cero credibilidades. El 99\% de nuestra gente cree en el documento de Greenpeace. Por 30 años el Gobierno y la industria salmonicultora han destruido nuestro mar" (Aqua, 2016g).

Los resultados de la investigación de Greenpeace permitieron dejar expuesta la caja negra en torno al evento y se observaron protocolos y procedimientos, elementos invisibles antes del desastre ambiental y que son parte del ensamblaje de los agentes, siendo foco de cuestionamientos por parte de las organizaciones de la sociedad civil en torno a la decisión de las autoridades de no aplicar criterios científicos que fundamenten tal decisión. Según Greenpeace: 
Todo indicaría que aquí falta el cumplimiento del protocolo de Londres y eso es gravísimo, para explicar un poco a qué nos referimos con esto, el protocolo de Londres dice que uno debe contar con diferentes hipótesis sobre los posibles impactos de este vertimiento y cada una de esas hipótesis debe estar debidamente fundamentada, con criterios científicos antes de realizar el vertimiento y antes de autorizar, esa información hoy día no está a la luz pública, cuáles son los estudios sobre el impacto, cuáles son los análisis de marea, cuáles son los análisis de corrientes que tomaron las autoridades para poder autorizar este vertimiento (CNN Chile, 2016, 7m08s).

Desde la experiencia y el conocimiento de la pesca artesanal del maritorio, los sindicatos de pescadores también cuestionaron el proceder del vertimiento, sobre todo el punto donde se realizó el vertimiento de salmones, según se corrobora en la siguiente cita: "Los botes nuestros quedaban llenos de grasa [...]. Si tú la botas a 70 millas para afuera, la grasa se dispersa con los vientos. En las noches hay siete cambios de viento, se dispersa pa cualquier parte, pero aquiíí... no la botaron ahí..." (Expresidenta de la CONAPACH, comunicación personal, 29 de junio de 2019)

Durante el desarrollo de la controversia, las estrategias de presión y la producción de conocimiento que usaron sus agentes permitieron mediatizar el discurso del vertimiento como responsable de la envergadura y toxicidad de la FAN. Por otro lado, la heterogeneidad de agentes que fueron ensamblándose en la trayectoria del conflicto, fue capaz de ampliar el alcance de esta versión del evento, conectando redes dentro y fuera del territorio en disputa. Por otro lado, la apertura de la caja negra del evento puso al descubierto una serie de dispositivos y protocolos que, al quedar expuestos a la observación, fueron cuestionados en su proceder y operatoria, de modo que se mantuvo abierta la controversia durante la etapa de mayor intensidad del conflicto.

FAN y los procesos de la industria del salmón

Este discurso se ha mantenido encapsulado dentro de un proceso socio-histórico que conecta la crisis de la marea roja con otros conflictos medioambientales relacionados con las operaciones de la industria salmonera y sus impactos en el ecosistema marino de la región. En el trasfondo de estos debates, se cuestiona el actual modelo de desarrollo en el territorio, donde el evento de 2016 revitalizó las críticas apuntando de nuevo como responsable de la crisis a la industria salmonera y su operación en los últimos 30 años. Así lo plantea el miembro del Comité de Protección del Borde Costero:

Lo que pasa es que la industria salmonera ha funcionado en los últimos 30 años en un sistema [...] casi cerrado. Nosotros somos un mar interior de Chiloé en un sistema cuyas capacidades de carga. Es decir, las capacidades de este sistema para reciclar, absorber o dispersar los contaminantes que genera la industria salmonera son desconocidos a pesar que la ley de pesca que ha mandatado a partir del año 2010 a la 
Subsecretaría de Pesca [...] las instrucciones para que realicen estudios de capacidades de carga en estos sistemas y la Subsecretaría de Pesca sencillamente ha hecho caso omiso de lo que la ley le mandata. (Ricardo Canales, 2016, 11m0s)

Profundizando en la historia de la industria en la región, desde su asentamiento ha provocado un fuerte proceso de transformación en diversas esferas de la vida en la zona, estableciendo una visión del desarrollo que se articula de manera directa a la producción de salmones para cubrir la demanda de los mercados internacionales. Sin embargo, como se mencionaba antes, en las últimas décadas la salmonicultura se ha visto expuesta a crisis medioambientales debido al aumento desregulado de su producción y a los problemas sanitarios en sus procesos, elementos que este discurso asume como el tema de fondo de la crisis, entre los que se encuentra la eutrofización de fondo marino, según se aprecia en la siguiente cita:

Estos son los centros anaeróbicos porque se superó la capacidad de carga del medio acuático. En este sedimento es imposible la vida acuática. Los salmoneros tiran salmones donde no puede haber vida acuática [...]. Sí, esto es ridículo, y ésta es la situación al 2013 [...] Miren la situación del estuario de Reloncaví [...] Ésa es la situación de Aysén y esto es eutrofización. No es necesario hacer más investigación científica para demostrar en general el estado del mar interior de Chiloé que los propios datos de SERNAPESCA. El sistema está colapsado, se terminó, caput, chao. (Miembro del Comité Protección del Borde Costero, actividad de observación)

Con el conocimiento científico sobre este fenómeno, este argumento plantea, como hipótesis, relacionar de modo causal la FAN con la crisis de la anemia infecciosa del salmón (virus ISA), evento que marcó un antes y un después en términos de sostenibilidad y crecimiento del sector. Ambos eventos quedaron conectados, lo cual dio continuidad histórico-espacial al conflicto, como refiere la siguiente cita: “En primer lugar, esto no es un fenómeno nuevo, esto es un fenómeno que ya se dio el año 2009 y esta marea roja a mi entender no es sino la continuidad del evento que se produjo el año 2009" (Ricardo Canales, 2016, $11 \mathrm{m0s})$.

Por otro lado, este argumento amplía su alcance realizando conexiones con las redes de poder arraigadas a lo largo de la historia entre la industria y el sector político del país. Los argumentos estaban centrados principalmente en favorecer, a través de leyes, a la industria salmonera por sobre otros actores para la obtención y gestión de los recursos del mar, además de otras prácticas, como la puerta giratoria, donde personeros de gobierno pasan del sector público al privado, lo cual fue puesto en tela de juicio por un diputado de la república: “No está de más recordar el rol que cumple la colonización del empresariado en la política, ¿quién es el representante de los salmoneros en Chile?, es Felipe Sandoval, quien fuera subsecretario de Pesca del señor Ricardo Lagos (expresidente de Chile)" (El Mostrador, 2016b). 
Si bien en la producción de conocimiento y en las investigaciones sobre marea roja hay consenso en torno a su dinámica y ciclo de vida, durante la controversia se apreciaron distintas posiciones que buscaron determinar si la Alexandrium catenella es una microalga o un dinoflagelado, lo cual abrió el debate sobre si su reproducción está asociada con condiciones naturales, climatológicas y oceanográficas, como señalan algunos expertos, o con el aporte de nutrientes (desechos) que realiza la industria salmonera. Un miembro del Comité del Borde Costero afirma lo siguiente:

Alexandrium catenella no es un alga, es un dinoflagelado. No es una planta, es un organismo miembro del reino de los protistas que está intermedio entre una planta y un animal, más animal que planta y por lo tanto no depende del sol, no tiene nada que ver el fenómeno del Niño ni el calentamiento global, ni el hoyo en la capa de ozono ni nada de eso con la proliferación que hoy día estamos sufriendo. Lo que sí tiene que ver son las descargas exageradas y por sobre las capacidades de carga del sistema respecto al nitrógeno flotante, porque el Alexandrium catenella se reproduce [se ríe] especialmente cuando hay nitrógeno en el agua, en la columna de agua. El fenómeno del Niño no pone nitrógeno. El nitrógeno lo genera la producción acuícola de la industria salmonera. (Velásquez, 2016, 15m0s)

La regulación y fiscalización de la actividad salmonera en la región emerge en los discursos mostrando una serie de falencias y de contradicciones dentro de la institucionalidad que han expresado distintos sectores durante el conflicto, lo cual es puesto en evidencia en las siguientes citas: “En Quellón entre el año 2009 y este año [2016] la industria salmonera en el interior del mar interior de Chiloé aumentó su producción hasta en 15 veces y nadie lo reguló [...] iy nadie lo reguló!" (Ricardo Canales, 2016, 11m0s).

El Servicio Nacional de Pesca, que es el encargado de fiscalizar, cuando tiene que ir a un lugar no tiene embarcación ni tiene la capacidad de subirse a una embarcación, e ir a [el lugar] por decir de alguna manera, de sorpresa a algún lugar. Siempre tiene que haber una conexión con la Armada, que [...] que se conecte, que se planifique, que se vaya al lugar eh [...] etcétera. Hay una gran dificultad. Y no solamente en el control de la salmonicultura, sino que, en el control de la pesca, también. (Director zonal de SERNAPESCA, INDH, 2016)

Por último, dentro de la trama argumentativa de este discurso, la misma ciencia es puesta en tela de juicio, pues se cuestiona su objetividad e independencia de la industria salmonera durante el desarrollo de la controversia. Cuestiona los centros de investigación y las universidades, los cuales reproducen los mismos patrones del modelo neoliberal, sustentando su accionar en la captación de recursos para la investigación de las enfermedades asociadas con el salmón y buscando soluciones que contribuyan en mejorar la eficiencia en el manejo sanitario de los centros de cultivo, lo cual es parte de los procesos de acumulación de capital de la industria. 
Las universidades, los centros de investigación como fuente de soluciones científicas, vean de lo que viven [...] de esto es lo que vive la academia. Vive de usar [el árbol] quillay para mejorar el metabolismo en crecimiento de los salmones. Acá la Universidad Católica de Valparaíso 290000000 millones de pesos esto lo [...] de un proyecto, 290000000 millones de pesos del año 1996 era más de medio millón de dólares y para qué se los dieron, para desarrollar la dirección y control del SRS [...] salmones, que son las bacterias que producen los salmones, y luego la de [universidad] Talca otros 6 millones para lanzar la vacuna, luego otros 45 millones para volver a lanzar la vacuna, mientras tanto el desarrollo compuesto también para el SRS. ¿Cuánto? 273000000 millones. Sumen eso [...] sumen. Eso se ha gastado para controlar el SRS en una sola página del FONDEF. ${ }^{3}$ (Miembro del Comité Protección del Borde Costero, actividad de observación)

Durante la evolución de la controversia, este argumento cuestiona la objetividad de la ciencia en Chile y muestra el entramado de poder existente en torno a la industria salmonera. Se aprecia en este discurso las críticas al Estado y la débil normativa en materia medioambiental. Por otro lado, mediante el conocimiento existente sobre la dinámica de la Alexandrium catenella, este discurso logró colocar en tela de juicio el argumento del fenómeno del Niño y el cambio climático, dado que, según esta postura, la capacidad de este microorganismo de reproducirse y captar nutrientes del medio marino depende más bien de los aportes de nitrógeno que produce la industria salmonera y no de variables externas.

FAN y la agencia del mar de Chiloé

Un discurso emergente dentro del conflicto fue la posición de los pueblos originarios de la región. Aquí elementos como el mar adquieren expresividad y agencia y, por lo tanto, interactúan en la política tal como la viven esas comunidades (Gudynas, 2014). En este aspecto, las comunidades Huilliches refieren que el daño causado por la FAN fue producto del vertimiento de salmones muertos en el mar, lo cual provocó la apertura ontológica del conflicto visibilizando el lazo entre lo humano y lo no humano, en este caso entre las comunidades mapuches-huilliches y el mar. Lo anterior se ve reflejado en la cita del cacique de Huentemó:

El mar se enojó, le decimos nosotros. Se enojó porque floreció y eso es rabia que tiene el mar. Hubo una contaminación. No es marea roja. Nosotros lo tenemos claro. Todos los que vivimos acá. Aquí uno conoce sus mares porque los está viendo todos los días. Aquí tenemos una mitología muy importante, muy variada, muy valiosa. $Y$ este mar es muy celoso con gente ajena. Y cuando le tiraron esos desechos al mar, el mar se enojó. (Greenpeace Chile, 2016b, 3m37s)

3 Fondo de Fomento al Desarrollo Científico y Tecnológico. 
Al mar se le atribuyen propiedades de sanación y purificación, además de la relación con sus ancestros y espíritus, quienes los protegen y dan equilibrio, como se describe en la siguiente cita:

A nuestro pueblo lo mataron porque siempre hemos sabido que somos de mar y de tierra. Amamos la naturaleza. En el mar hay muchas personas que han muerto y son los espíritus que nos protegen a nosotros, porque nosotros vivimos de esto, esto nos da fortaleza. Tenemos el mar, por eso no necesitamos psicólogo. No voy al médico cuando me siento enferma, al hospital, voy al mar. Ahí me arrodillo y le pido que me dé fortaleza. No voy al hospital porque sé que ahí me voy a enfermar más. Pero sí voy al mar. Si tengo pena voy allá, corro, me tiro un piquero y eso me ayuda y pienso que muchos de mis hermanos son así. Es un todo para nosotros. (INDH, 2016)

Las categorías antes descritas nos muestran la heterogeneidad de discursos que emergieron debido a la fractura en el conocimiento científico sobre el fenómeno. Al quedar expuesta la caja negra a la observación, se visibilizan los distintos esfuerzos de los agentes por sostener versiones de la realidad que se intersectaron y entraron en disputa. Dadas las características y el nivel de incertidumbre producto de su emergencia, las FAN se hicieron múltiples durante el desarrollo de la controversia.

\section{Conclusiones}

Los resultados obtenidos en la investigación muestran la compleja trama de poder subyacente en la Isla Grande de Chiloé. Se evidencia cómo la marea roja fue capaz de articular un complejo entramado de asociaciones entre agentes humanos y no humanos, (microorganismos y tecnologías) en el cual se encontraron imbricadas naturaleza, política, ciencia, tecnología y legislación. Entender la controversia, desde la arista del conocimiento científico, permite apreciar con mayor detalle los efectos performativos del saber experto y sus esfuerzos por objetivar una versión homogénea de la realidad. Dicho conocimiento tiene como trasfondo un modelo de desarrollo extractivista que busca validar el discurso del cambio climático y el fenómeno del Niño a fin de despolitizar la crisis. Esta versión oficial de los hechos entró en disputa con un grupo heterogéneo de versiones que se mediatizaron en el desarrollo del conflicto. Lo anterior muestra la articulación entre ciencia y política, donde se observa cómo el Estado y la academia se unieron en la coproducción de conocimiento con la finalidad de cerrar la controversia. Sin embargo, esta estrategia sufre un quiebre por la arista del vertimiento de salmones muertos que dejó abierto el espacio para que gremios como el de la pesca artesanal establecieran redes de colaboración dentro y fuera del territorio, además de la producción de conocimiento que sintetizó el informe de la ONG Ambientalista Greenpeace manteniendo la apertura del conflicto. Estos dos discursos fueron los que mantuvieron una mayor producción 
mediática y los que marcaron los debates en torno a la FAN en 2016. Por otro lado, se activaron discursos que se encontraban instalados con anterioridad relacionados con el impacto que tiene la industria salmonera en el ecosistema marino de la isla - debido a una serie de crisis medioambientales que había vivido esta industria en el pasado. Dichos discursos mostraron las redes de poder existentes de este actor dentro del territorio. También fue posible apreciar cómo la naturaleza adquirió expresividad y agencia durante la crisis, sobre todo en el discurso de los pueblos originarios, lo cual mostró el lazo existente entre el mar y las comunidades Huilliches de la isla, elementos que muchas veces quedan invisibilizados por la ontología dominante (Sepúlveda y Sundberg, 2017).

Lo anterior abre la discusión sobre si las estrategias de cierre de las controversias logran estabilizar los conflictos o si más bien estas crisis no logran cerrarse, lo cual tiene efectos acumulativos en el tiempo. En el caso de la Isla Grande de Chiloé, la crisis de 2016 se clausuró con el levantamiento de la alerta sanitaria por parte de las autoridades de salud, medida que permitió que todas las actividades relacionadas con el mar volvieran a la normalidad. Esto puso en evidencia cómo la FAN se estabilizó por sí misma, siendo un nodo alrededor del cual se articulan, para su control y seguimiento en contexto de laboratorio, un conjunto de agentes que amplían sus redes de distinto tipo en torno al maritorio de Chiloé, lo que mantiene la controversia en estado latente. Dos años después del evento, la Corte Suprema de Chile (2018) acoge el recurso de protección que presentaron los sindicatos de pescadores artesanales en el que se denuncia el incumplimiento de los organismos públicos en torno al vertimiento de salmones. La Corte dictaminó la incorporación de nuevas medidas y nuevos protocolos, además de solicitar continuar con las investigaciones científicas y administrativas que contribuyan a impedir la repetición de lo ocurrido en 2016. Sin embargo, queda la impresión de que nadie se hizo responsable del vertimiento.

El análisis de esta controversia nos muestra lo politizado que se encuentra el mar de la Isla Grande de Chiloé, donde la emergencia de la marea roja develó las asimetrías de poder existentes en torno a los bienes de uso común.

\section{Referencias}

Asdal, K. (2003). The Problematic Nature of Nature: The post-constructivist challenge to environmental history. History and Theory (42), 60-74. Recuperado de https: / /www.jstor.org/stable/3590679?seq=1

AQUA. (2 de mayo de 2016a). Microalga causante de la marea roja aumenta en intensidad y extensión. Recuperado de http://www.aqua.cl/ 2016/05/02/ microalga-causante-de-la-marea-roja-aumenta-en-intensidad-y-extension/\#

AQUA. (2 de mayo de 2016b). Protestas de pescadores en distintos puntos de Los Lagos. Recuperado de http://www.aqua.cl/ 2016/05/02/protestas-de-pescadores-en-distintos-puntos-de-los-lagos/

AQUA. (9 de marzo de 2016c). Vertimiento de salmones muertos sería a 75 millas mar adentro de la Isla de Chiloé. Recuperado de http://www.aqua. 
cl/2016/03/09/bloom-vertimiento-de-salmones-muertos-seria-a-75-millasmar-adentro-de-la-isla-de-chiloe/

AQUA. (5 de septiembre de 2016d). Colegio de Biólogos Marinos de Chile por marea roja: "Nos preocupa el nivel de desinformación”. Recuperado de http:// www.aqua.cl/2016/05/06/colegio-de-biologos-marinos-de-chile-por-marea-roja-nos-preocupa-el-nivel-de-desinformacion/

AQUA. (5 de mayo de 2016e). Marea roja: el acertijo científico-sanitario que golpea al sur de Chile. Recuperado de https://www.aqua.cl/2016/05/05/ marea-roja-el-acertijo-cientifico-sanitario-que-golpea-al-sur-de-chile/\#

AQUA. (5 de septiembre de 2016f). Estudio de Greenpeace asevera que vertido de salmónidos causó crisis socioambiental. Recuperado de http://www. aqua.cl/2016/09/05/estudio-greenpeace-concluyo-vertido-salmonidos-desato-la-crisis-socioambiental/

AQUA. (14 de septiembre de 2016g). El cara a cara por el vertimiento de salmones en Chiloé. Recuperado de http://www.aqua.cl/2016/09/14/el-cara-acara-por-el-vertimiento-de-salmones-en-chiloe/

Armijo, J., Bravo, A., y Molina, E. (2018). La crisis de la marea roja del 2016 en el sur de Chile: influencia de la eliminación de salmones muertos con la expansión de floraciones algales nocivas. En XXXVIII Congreso de Ciencias del Mar. Las Ciencias Marinas en tiempos de cambio global (p. 230). Valdivia: Universidad Austral. Recuperado de https://n9.cl/13rnj

Biblioteca del Congreso Nacional de Chile. (16 de mayo de 2016a). Marea roja. Departamento de Estudios, Extensión y Publicación. Recuperado de https:// webcache.googleusercontent.com/search?q=cache:CULZQq0l9X0J:https:// www.camara.cl/verDoc.aspx\%3FprmTIPO\%3DDOCUMENTOCOMUNICACIONCUENTA\%26prmID\%3D14444+\&cd=3\&hl=es\&ct=clnk\&gl=cz\&client=firefox-b-d

Biblioteca del Congreso Nacional de Chile. (10 de mayo de 2016b). Decreto 409, Declara como afectada por la catástrofe, derivada de la aparición del fenómeno denominado "Marea Roja”, al borde costero de la Región de Los Lagos. Recuperado de https://www.leychile.cl/Navegar?idNorma=1090221\&idVersion $=2016-05-10$

Bińczyk, E. (2013). The problem of skepticism towards climate change and post-constructivism. Cultural Review, 4866. Recuperado de http://www. ejournals.eu/Przeglad-Kulturoznawczy/Przeglad-Kulturoznawczy-2013/Numer-1-15-2013/art/1108/

Buschmann, A., Farías, L., Tapia, F., Varela, D., y Vásquez, M. (noviembre de 2016). Informe final. Comisión Marea Roja. Recuperado de http://www.economia.gob.cl:http://www.economia.gob.cl/wpcontent/uploads/2016/11/ InfoFinal_ComisionMareaRoja_24Nov2016-1.compressed.pdf

Bustos, B., Prieto, M., y Barton, J. (2017). Ecología política en Chile. Naturaleza, propiedad, conocimiento y poder. Santiago: Universitaria.

Campbell, L., y Godfrey, M. (2010). Geo-political genetics: claiming the commons through species mapping. Geoforum (41), 897-907 Recuperado de https://www.sciencedirect.com/science/article/abs/pii/s0016718510000771

Canales, R. (10 de mayo de 2016). Héctor Kol. La bancada salmonera ha votado a favor de la ley corrupta de pesca. YouTube. https://www.youtube.com/ watch?v=YyN9bc_Lokc 
Casas, L. (18 de agosto de 2016). Comisión científica concluye que marea roja no tuvo relación con vertimiento de salmones. BiobioChile. Recuperado de https://www.biobiochile.cl/noticias/nacional/chile/2016/08/18/comision-cientifica-concluye-que-marea-roja-no-tuvo-relacion-con-vertimiento-de-salmones.shtml

CNN Chile. (14 de mayo de 2016). Greenpeace acusa crisis en Chiloé. YouTube. https: / / www.youtube.com/watch?v=ZJvAyzTjo5I

Corte Suprema de Chile. (2018). Sentencia Corte Suprema 22 de mayo de 2018 por el acto de vertimiento de salmones en altamar. Recuperado de http:// www. derecho.uchile.cl/centro-de-derecho-ambiental/columnas-de-opinion/prof-pilar-moraga-comentario-sentencia-cs-de-22-de-mayo-de-2018

DIRECTEMAR. (4 de marzo de 2016). Otorga permiso para efectuar vertimiento de emergencia de desechos de pescado en la jurisdicción de la Gobernación Marítima de Puerto Montt. Recuperado de https: / /www.directemar.cl/directemar/site/artic/20170324/asocfile/20170324094416/10_resord_vertimiento_114.pdf

El Mostrador. (18 de agosto de 2016a). Comisión científica determinó que el vertimiento de salmones en la zona de Chiloé no tiene relación directa con la marea roja. Recuperado de http://www.elmostrador.cl/noticias/ pais/2016/08/18/comision-cientifica-determino-que-el-vertimiento-de-salmones-en-la-zona-de-chiloe-no-tiene-relacion-directa-con-la-marea-roja/

El Mostrador. (11de mayo de 2016b). Crisis en Chiloé: Boric apunta a subsecretario de Pesca de Ricardo Lagos que ahora es representante de las salmoneras. Recuperado de https://www.elmostrador.cl/noticias/pais/2016/05/11/ crisis-en-chiloe-boric-apunta-a-subsecretario-de-pesca-de-ricardo-lagos-que-ahora-es-representante-de-las-salmoneras /

Escobar, A. (2010). Ecologías políticas postconstructivistas. International Handbook of Environmental Sociology. Recuperado de http://www.sustentabilidades.usach.cl/sites/sustentable/files/paginas/02-05.pdf

Escobar, A. (2013). En el trasfondo de nuestra cultura: la tradición racionalista y el problema del dualismo ontológico. Tabula Rasa (18), 15-42. Recuperado de http: / /www. revistatabularasa.org/numero-18/01escobar.pdf

Escobar, A. (2016). Autonomía y diseño: la realización de lo comunal. Popayán: Universidad del Cauca. Recuperado de http://www. maestriadesarrollo.com/ sites/default/files/publicaciones/autonomia-y-diseno-arturo-escobar-ok.pdf

Espinoza, O., y Besoaín, V. (2018). Patrón de distribución vertical de Alexandrium catenella en fiordos y canales del Sur de Chile. En XXXVIII Congreso de Ciencias del Mar. Las Ciencias Marinas en Tiempos de Cambio Global. (p. 256). Valdivia: Universidad Austral. Recuperado de https://n9.cl/13rnj

Forlano, L. (2017). Posthumanism and design. She Ji: The Journal of Design, Economics and Innovation, 3(1), 16-29. Recuperado de https://doi.or$\mathrm{g} / 10.1016 / \mathrm{j}$.sheji.2017.08.001

Gobernación Provincia de Chiloé. (2018). Información geográfica: Provincia de Chiloé. Recuperado de http://www.gobernacionchiloe.gov.cl/geografia/

Greenpeace Chile. (2016a). Reporte crisis social ambiental en Chiloé. Recuperado de https://n9.cl/rq3x 
Greenpeace Chile. (10 de junio de 2016b). Chiloé: el día que el mar se enojó. YouTube. https://www.youtube.com/watch?v=AE7M3c_Prtl

Gudynas, E. (2014). Ecología política: ideas preliminares sobre concepciones, tendencias, renovaciones y opciones latinoamericanas. Centro Latinoamericano de Ecología Social (CLAES). Recuperado de http://ambiental.net/wpcontent/uploads/2014/10/EcologiaPoliticaDefinicionesTendenciasGudynasDT2014.pdf

Guo, X., Uehara, A., Ravidran, A., Bryant, S., Hall, S., y Moczydlowski, E. (1987). Kinetic basis for insensitivity to tetrodoxin and saxitoxin in sodium channels of canine heart and denervated rat skeletal muscle. Biochemistry (26): 75467556. Recuperado de https://pubs.acs.org/doi/pdf/10.1021/bi00398a003

Guzmán, L., Espinoza-González, O., Pinilla, E., Besoain, V., Calderón, M., Cáceres, J., Iriarte, L., Muñoz, V., Martínez, R., Hernández, C., Tocornal, M., y Carbonell, P. (2018). Importancia de los procesos atmosféricos y oceanográfico en la dinámica de distribución y abundancia de Alexandrium catenella en la floración de 2018. XXXVIII Congreso de Ciencias del Mar. Las Ciencias Marinas en Tiempos de Cambio Global (p. 257). Valdivia: Universidad Austral. Recuperado de https://n9.cl/13rnj

Instituto Nacional de Derechos Humanos (INDH). (2016). Informe misión de observación situación socioambiental región de Los Lagos. Recuperado de https://n9.cl/3krv

Instituto Nacional de Estadística (INE). (2017). Censo 2017. Recuperado de https: / / resultados.censo2017.cl/Region?R=R10

Jasanoff, S. (2004). States of Knowledge: The Co-production of Science and Social Order. London: Routledge.

Knol, M. (2011). Constructivism and post-constructivism: the methodological implications of employing a postconstructivist research approach. Recuperado de https: / / munin.uit.no/bitstream/handle/10037/4106/article.pdf?sequence $=4 \&$ isAllowed $=\mathrm{y}$

Latour, B. (2001). La esperanza de Pandora. Ensayos sobre la realidad de los estudios de las ciencias. Barcelona: Gedisa.

Latour, B. (2008). Reensamblar lo social. Una introducción a la teoría del actor-red. Buenos Aires: Manantial.

Latour, B. (2012) [2007]. Nunca fuimos modernos. Ensayos de antropología simétrica. Buenos Aires: Siglo Veintiuno.

Latour, B., y Woolgar, S. (1995). La vida en el laboratorio. La construcción de los hechos científicos. Madrid: Alianza.

Martínez, N. (5 de mayo de 2016). El documento que autorizó vertimiento de 9000 toneladas de salmón descompuesto en el sur. Biobiochile. Recuperado de http://www.biobiochile.cl/noticias/2016/05/05/documento-comprueba-vertimiento-de-9-mil-toneladas-de-salmones-descompuestos-en-alta-

Masotti, I., Uribe, F., Malhue, G., Vera, P., y Cádiz, A. (2018). Evolución temporal e impactos de las floraciones de algas nocivas en el sur de Chile. En XXXVIII Congreso de Ciencias del Mar. Las Ciencias Marinas en tiempos de cambio global (p. 260). Valdivia: Universidad Austral. Recuperado de https:// n9.cl/13rnj 
Merlinsky, G. (2017). Cartografía del conflicto ambiental en Argentina. Notas teórico-metodológicas. Acta Sociológica (43). Recuperado de https://www. sciencedirect.com/science/article/pii/S0186602817300555

Ministerio de Salud de Chile (MINSAL). (2008). Programa Nacional de Vigilancia y Control de las Intoxicaciones por Fenómenos Algales Nocivos ("Marea Roja”). Recuperado de http://webcache.googleusercontent.com/search?q=cache:G0cEy1OdGgJ:www. minsal.cl/portal/url/item/6b5e9c3b19e27cdde04001011f016a72.pdf $+\& c d=1 \& h l=e s \& c t=c l n k \& g l=c z \& c l i e n t=f i r e f o x-b-d$

Mol, A. (1999). Ontological politics: a word and some questions. Board of The Sociological Review. Recuperado de https: / / onlinelibrary.wiley.com/doi/ep$\mathrm{df} / 10.1111 / \mathrm{j} .1467954 X .1999 . t b 03483 . x$

Orlandi, E. (2012). Análisis de discurso. Principios y procedimientos. Santiago: LOM Ediciones.

Organización Marítima Internacional (OMI). (23 de noviembre de 2020). Convenio y protocolo de Londres. Recuperado de https://www.imo.org/es/OurWork/ Environment/Paginas/London-Convention-Protocol.aspx

Pizarro, G., Garrido, C., Zamora, C., Alarcón, C., Raimapo, L., Salgado, P., Pacheco, H., Guzmán, L., Paz, B., Álvarez, P., y Faure, M. (2015). Distribución de Alexandrium catenella y de toxinas paralizantes en el fitoplancton y mariscos entre el estrecho de Magallanes y Tierra del Fuego (primavera 2010). Revista Ciencia y Tecnología del Mar. Recuperado de http://www.cona.cl/ ctmol2/vol36/gemita_pizarro.pdf

Sepúlveda-Luque, C., Lara-Sutulov, M., Pérez, S., Guerra, F., Rodríguez, C., y Pino, A. (2018). De la invisibilidad a la multiplicidad: movilizaciones, ontologías e imaginarios urbanos en torno a la defensa de los humedales en Valdivia. Revista Austral de Ciencias Sociales (35). Recuperado de http: / / revistas. uach.cl/index.php/racs/article/view/4192

Sepúlveda, C., y Sundberg, J. (2017). Apertura ontológica, multiplicidad y performación: explorando una agenda post humanista en ecología política a partir del desastre del río Cruces en Valdivia. En B. Bustos, M. Prieto y J. Barton (eds.), Ecología política en Chile. Naturaleza, propiedad, conocimiento y poder (pp. 167-186). Santiago: Universitaria.

Velásquez, A. (6 de mayo de 2016). La industria salmonera culpable de la marea roja. Biólogo Héctor Kol. Primera parte. YouTube. https: / /www.youtube. $\mathrm{com} /$ watch?v=1VwZOql645Q 